\title{
Effect of the post-heat treatment on the properties of medium density particleboard of Eucalyptus sp.
}

\author{
Ticyane Pereira Freire Sabino ${ }^{1}$ (]) \\ Paula Gabriella Surdi ${ }^{2}$ (D) \\ Alan Pereira Vilela ${ }^{1}$ (1) \\ Stefânia Lima Oliveira Metzker ${ }^{1}$ \\ Nayane Pereira Freire Coelho ${ }^{1}$ (B) \\ Tiago José Pires de Oliveira ${ }^{1}$ \\ Rafael Farinassi Mendes ${ }^{1}$ \\ ${ }^{1}$ Universidade Federal de Lavras, Lavras, MG, Brasil. \\ ${ }^{2}$ Universidade Federal de Viçosa, Viçosa, MG, Brasil.
}

\begin{abstract}
Heat treatment aims to reduce the compression stresses generated during the panel production, improving its dimensional stability and providing greater resistance to attack by xylophagous organisms, despite decreasing the mechanical properties. This work aimed to evaluate the physical-mechanical properties of medium density particleboard (MDP) of Eucalyptus sp. subjected to post-heat treatment with two temperature levels $\left(200\right.$ and $\left.260^{\circ} \mathrm{C}\right)$ and two periods (5 or 10 minutes). The apparent density, water absorption and thickness swelling (TS) after 2 and $24 \mathrm{~h}$, internal bonding, MOE and MOR in static bending were evaluated. The post-heat treatment at $200{ }^{\circ} \mathrm{C}$ for 5 minutes was the most efficient, improving the TS, with smaller reductions in the mechanical properties. The temperature had a greater influence in the first hours of immersion in water (TS2h), while for a longer period (TS24h) the heat treatment time was more effective. The temperature influenced the mechanical properties more negatively than the heat treatment time.
\end{abstract}

Keywords: Composites, Dimensional stability, Physical-mechanical properties, Thermal modification.

\section{INTRODUCTION}

Particleboards are one of commonly produced wood materials in the world with application in many branches of industry, in particular in furniture, construction or packaging industries (Borysiuk et al., 2019). World production of wood panels (particleboard) was 97.5 million $\mathrm{m}^{3}$ in 2019 (FAO, 2020), with Brazil accounting for 3.2 million $\mathrm{m}^{3}$, with $3.2 \%$ increase in the production of medium density particleboard (MDP) in relation to the previous year (IBÁ, 2019).

The particleboard provides the advantages of using lower quality raw materials and adequate mechanical properties and surface finish (Mendes et al., 2018; Narciso et al., 2020), but the dimensional instability due its hygroscopic behavior is one of the shortcomings (Salca \& Hiziroglu, 2014; Majka et al., 2016). Many studies have been carried out using different modification processes to decrease such disadvantage (Lee et al., 2017; Özgenç et al., 2017). Heat treatment is reported to be an effective method since it significantly improves the hydrophobic properties and dimensional stability of wood and wood products (Poncsák et al., 2007; Tarmian \& Mastouri, 2019; Soratto et al., 2020).

Heat treatment also changes the wood structure and degrades partially cell wall compounds and wood extractives (Nuopponen et al., 2003; Silva et al., 2017; Melo et al., 2018). Although there is also a mass loss in lignin and cellulose, the thermal degradation of the hemicelluloses during heat treatment is much more intense and expressive (Van Der Stelt et al., 2011; Silva et al., 2017), due to its heterogeneous structure, amorphous structure and low molecular weight relative to the other polymers in the wood (Figueroa \& Morais, 2009). In wood panels, this treatment also aims to reduce the compression stresses generated during the panel manufacturing process (Del Menezzi et al., 2009; Mendes et al., 2013a).

There are two heat treatment procedures for the wood panels: (i) the pre-treatment performed in the raw material 
of panels, i.e., in the particles (Ayrilmis et al., 2011; Mendes et al., 2013a; Mendes et al., 2013b; Ribeiro et al., 2020), and (ii) the post-treatment performed in the panels after being consolidated and stabilized (Mendes et al., 2013b; Carvalho et al., 2015; Oliveira et al., 2017; Hill et al., 2021). Therefore, regardless of how it is applied, the heat treatment consists of the application of temperature between 100 and $250{ }^{\circ} \mathrm{C}$ in the wood or wood products (Kocaefe et al., 2010; Silva et al., 2018; Wang et al., 2018).

Thus, some researches have been aiming to evaluate its influence on MDP (Carvalho et al., 2015; Melo et al., 2018), medium density fiberboard - MDF (Lee et al., 2015; Oliveira et al., 2017; Wang et al., 2020), Plywood (Lunguleasa et al., 2018; Bekhta, 2020) and oriented strand board - OSB (Okino et al., 2007; Mendes et al, 2013ab). The results were promising in most cases and the heat treatment in already consolidated panels provided an improvement in material's dimensional stability and resistance to the attack of xylophagous organisms, despite decreasing the mechanical properties.

In order to obtain a treatment that improves the dimensional stability of eucalyptus panels with the least possible effect on the reduction of mechanical properties, the objective of this work was to evaluate the physical and mechanical properties of MDP subjected to post-heat treatment with two temperature levels and two times of duration.

\section{MATERIAL AND METHODS}

\subsection{Obtaining of material}

One commercial MDP produced with Eucalyptus sp. particles, urea-formaldehyde adhesive and dimensions of 2.750 $\mathrm{x} 1.830 \times 0.015 \mathrm{~m}$ (length, width and thickness, respectively) was evaluated. The panel was cut in specimens with dimensions of $50 \times 50 \mathrm{~cm}$ (length and width) and acclimatized in a room with a temperature of $20 \pm 2{ }^{\circ} \mathrm{C}$ and relative humidity of $65 \pm 5 \%$, up to constant mass.

The choice to use only one commercial panel, and its division in specimens for heat treatment in a laboratory press, aimed at greater homogenization of the initial properties of the panel for the different treatments, allowing the evaluation of the effect of the heat treatment on its physical and mechanical properties.

\subsection{Heat treatment}

The heat treatment of the samples was performed in a hydraulic press for 5 and 10 minutes at 200 and $260^{\circ} \mathrm{C}$ (Table 1), with three replications for each treatment. The pressure used was $0.5 \mathrm{kgf} / \mathrm{cm}^{2}$ to promote a good contact between the press plates and the sample and hence facilitate the temperature conduction. The parameters evaluated in this study were based on Oliveira et al. (2017) and Carvalho et al. (2015).

Table 1. Description of heat treatments.

\begin{tabular}{|ccc|}
\hline Treatments & Temperature $\left({ }^{\circ} \mathbf{C}\right)$ & Time $(\mathbf{m i n})$. \\
\hline Control & - & - \\
T1 & 200 & 5 \\
T2 & & 10 \\
T3 & 260 & 5 \\
T4 & & 10 \\
\hline
\end{tabular}

\subsection{Physical and mechanical characterization of the samples}

Samples of MDP, treated and untreated, were cut using a circular saw. The apparent density, water absorption (WA) and thickness swelling (TS) after $2 \mathrm{~h}$ and $24 \mathrm{~h}$ of immersion, and internal bonding (IB) were performed following the requirements of the ASTM - D1037 standard (ASTM, 2012). The modulus of rupture (MOR) and modulus of elasticity (MOE) in static bending were determined according to the DIN 52362 NHSS standard (DIN, 1982). The EN 312 standard (ECS, 2003) was used as a comparison parameter for the results obtained.

\subsection{Statistical analysis}

The results of the physical and mechanical properties in relation to the heat treatment of the MDP samples were analyzed in a completely randomized design, in a factorial arrangement with two temperatures $\left(200\right.$ and $\left.260{ }^{\circ} \mathrm{C}\right)$ and two times ( 5 and 10 minutes) and a control (MDP without heat treatment). The means were grouped using the ScottKnott test $(\mathrm{p} \leq 0.05)$. The results considered the values of the control and were submitted to the Dunnett test $(\mathrm{p} \leq 0.05)$.

\section{RESULTS AND DISCUSSION}

\subsection{Physical properties}

Table 2 shows the values of apparent density and thickness obtained for samples with and without heat treatment. The apparent density was $9.5 \%$ higher in the untreated (control) than in samples treated for 10 minutes at $260^{\circ} \mathrm{C}$ (Table 2). The NBR 14810 standard (ABNT, 2018) establishes that medium density panels are those with values between 0.51 and $0.75 \mathrm{~g} / \mathrm{cm}^{3}$. In view of this classification, only samples treated at $260^{\circ} \mathrm{C}$ for $10 \mathrm{~min}$ do not fit the category of medium density panels. 
The decrease in the apparent density with the increase in the heat treatment time and temperature is due partially to the mass loss of the MDP by the thermochemical degradation of its volatilized constituents; this reduces the mass ratio over the sample volume and, consequently, the apparent density (Mendes et al., 2013a; Ribeiro et al., 2020). In additional, the thickness increased with the increase in the heat treatment temperature and time from $15.58 \mathrm{~cm}$ (control) to $16.08 \mathrm{~cm}$ in the $260^{\circ} \mathrm{C} / 10 \mathrm{~min}$ treatment (Table 2). The reduction of the apparent density of the material is linked to the increase of the sample's final thickness due to the partial release of compression stresses (Mendes et al., 2013b). According to Maloney (1993), an increase or expansion in the thickness occurs for most of the particleboards following the opening of the hot press, at the end of pressing, following the pressing pressure relaxation.

Mendes et al. (2013a) when evaluating post-heat treatment in OSB panels at temperatures of $220^{\circ} \mathrm{C}$ for 12 minutes, observed a reduction in the panels density between 4 to $6.7 \%$. Ribeiro et al. (2020) when studying the heat treatment in sugarcane bagasse MDP at temperatures of 170, 200 and 230 ${ }^{\circ} \mathrm{C}$ observed density reductions in the range of 5.5 to $6.3 \%$. Carvalho et al. (2015) applied heat treatment at 200, 230 and $260{ }^{\circ} \mathrm{C}$ for 8 and $12 \mathrm{~min}$ in MDP produced with sugarcane bagasse and observed a reduction from $0.0 \%$ to $8.2 \%$ in the final density of panels by increasing the temperature and the duration of treatment. In this study, the reduction of apparent density was about 4.8 to $9.5 \%$.

Table 2. Effect of heat treatment on apparent density and thickness of MDP.

\begin{tabular}{|c|c|c|}
\hline Treatments & Apparent density $\left(\mathrm{g} / \mathrm{cm}^{3}\right)$ & Thickness (cm) \\
\hline Control & $0.63^{(0.01)} \mathrm{a}$ & $15.58^{(0.07)} \mathrm{a}$ \\
\hline $200^{\circ} \mathrm{C} / 5 \mathrm{~min}$ & $0.60^{(0.01)} \mathrm{b}$ & $15.77^{(0.12)} \mathrm{b}$ \\
\hline $200^{\circ} \mathrm{C} / 10 \mathrm{~min}$ & $0.60^{(0.01)} \mathrm{b}$ & $15.73^{(0.10)} \mathrm{b}$ \\
\hline $260^{\circ} \mathrm{C} / 5 \mathrm{~min}$ & $0.60^{(0.01)} \mathrm{b}$ & $15.78^{(0.10)} \mathrm{b}$ \\
\hline $260^{\circ} \mathrm{C} / 10 \mathrm{~min}$ & $0.57^{(0.01)} \mathrm{c}$ & $16.08^{(0.05)} \mathrm{c}$ \\
\hline
\end{tabular}

Table 3 shows the values of water absorption and thickness swelling obtained for samples with and without heat treatment. All values of WA2h of the heat-treated samples differed statistically from the control, increasing from 15.16 to $32.42 \%$, depending of the time and temperature used. The higher water absorption is due to the compression stresses present in the MDP, which are released after the heat treatment, increasing its thickness (Table 2) and allowing more water entering the interior in a shorter time. After $24 \mathrm{~h}$ contact with water, this effect of heat treatment is no longer observed, since the time is sufficient for all the hygroscopic sites of the material to have contact with the water.

It was observed that the increase provided by the release of pressing pressures of eucalyptus MDP had a more marked effect than the thermal degradation of hemicelluloses. Thus, the water absorption of the samples was not reduced, as observed by other authors (Tjeerdsma \& Militz, 2005; Ayrilmis et al, 2009; Carvalho et al, 2015). This fact may be associated, besides the release of pressing pressures, with the higher thermal depolymerization of the cellulose that occurs between the temperatures 200 and $280^{\circ} \mathrm{C}$ (Figueroa \& Moraes, 2009), being more pronounced from $240{ }^{\circ} \mathrm{C}$ (Cavdar et al., 2014) what could favor the water absorption of eucalyptus wood.

Table 3. Effect of heat treatment on WA and TS of MDP.

\begin{tabular}{ccccc}
\multirow{2}{*}{ Treatments } & WA2h & WA24h & TS2h & TS24h \\
\cline { 2 - 5 } & \multicolumn{4}{c}{$\%$} \\
Control & $26.19^{(3.43)}$ & $67.87^{(2.20)}$ & $10.16^{(1.37)}$ & $19.36^{(0.99)}$ \\
$200^{\circ} \mathrm{C} / 5 \mathrm{~min}$ & $33.26^{(4.83) *}$ & $69.57^{(5.81)} \mathrm{ns}$ & $8.36^{(0.66) *}$ & $16.82^{(1.23) *}$ \\
\hline $200^{\circ} \mathrm{C} / 10 \mathrm{~min}$ & $30.55^{(6.38) *}$ & $69.92^{(6.92)} \mathrm{ns}$ & $7.53^{(1.07) *}$ & $18.79^{(1.63)} \mathrm{ns}$ \\
$260^{\circ} \mathrm{C} / 5 \mathrm{~min}$ & $30.39^{(6.69) *}$ & $64.74^{(8.99)} \mathrm{ns}$ & $9.03^{(0.27)} \mathrm{ns}$ & $16.68^{(0.34) *}$ \\
\hline $260^{\circ} \mathrm{C} / 10 \mathrm{~min}$ & $34.68^{(6.46) *}$ & $68.56^{(5.35)} \mathrm{ns}$ & $10.05^{(0.55)} \mathrm{ns}$ & $17.82^{(0.84)} \mathrm{ns}$ \\
\hline
\end{tabular}

${ }^{*}$ Differences, at the same column, among treatments and the control by the Dunnett test $(\alpha=0.05)$. ns does not differ, at column, from the control treatment by the Dunnett's test $(\alpha=0.05)$. The standard deviation is indicated in parentheses.

Interactions were not observed between both temperatures $\left(200\right.$ and $260{ }^{\circ} \mathrm{C}$ ) and both times (5 and $10 \mathrm{~min}$ ) of heat treatment when evaluating the properties of WA2h and WA24h, as well as no effect of the level of temperature and time of heat treatment was verified when evaluated separately.

The TS2 $\mathrm{h}$ values of samples heat-treated at $200^{\circ} \mathrm{C}$ differed statistically from the control, showing a reduction of $17.71 \%$ and $25.86 \%$ for the 5 and 10 minutes periods, respectively (Table 3). For TS24h, the treatments at 200 and $260{ }^{\circ} \mathrm{C}$ with duration of 5 minutes showed a significant improvement in relation to samples without heat treatment (control), because the values of this property reduced $13.12 \%$ and $13.84 \%$, respectively (Table 3).

Winandy and Krzysik (2007) studied the temperature and time effects of heat treatment on the properties of MDF panels and affirm that the decrease in thickness swelling values is related to the inhibition of moisture absorption of the material due to the reduction of hemicellulose present in wood. While Sivonen et al. (2002) explain that heat treatment increases the degree of entanglement within the lignin matrix and that this fact may be associated with the reduced hygroscopicity of thermally treated wood, thus improving the dimensional stability of the material. In the case of chemical modification, the hemicelluloses are initially broken down into monomeric 
structures, which are then dehydrated in aldehydes and form furfural units when derived from the pentoses and hydroxymethylfurfural units when derived from the hexoses, thus rendering a material less hygroscopic (Tjeerdsma \& Militz, 2005; Yildiz \& Gumuskaya, 2007; Winandy \& Krzysik, 2007; Uimonen et al., 2020; Hill et al., 2021).

The reductions in thickness swelling values are also associated with the release of compression stress before the panel is exposed to moisture (Carvalho et al., 2015). Del Menezzi et al. (2008) explain that the stress releases are due to the nature of polymers that compose the wood, mainly lignin, which are viscoelastic materials, i.e., the polymer becomes viscous with increasing temperature, losing its stiffness and hence releasing the compression stresses.

Table 4 shows that there were interactions between the two temperatures $\left(200\right.$ and $\left.260{ }^{\circ} \mathrm{C}\right)$ and the two times $(5$ and $10 \mathrm{~min}$ ) of the heat treatment in relation to the values of TS2 $h$ and TS24h. The increase of temperature and time had a negative effect on the TS2h property with highest value in the treatment of $10 \mathrm{~min}$ and $260^{\circ} \mathrm{C}$. In the TS $24 \mathrm{~h}$ property, there was a significant effect of the heat treatment time only at the temperature of $200{ }^{\circ} \mathrm{C}$, and the duration of $10 \mathrm{~min}$ showed the highest average value of swelling.

Table 4. Interactions between temperature and heat treatment time on the TS2h and TS24h of MDP.

\begin{tabular}{|c|c|c|}
\hline \multirow{2}{*}{ Temperature/Time } & \multicolumn{2}{|c|}{ TS2h (\%) } \\
\hline & $5 \mathrm{~min}$ & $10 \mathrm{~min}$ \\
\hline $200^{\circ} \mathrm{C}$ & $8.36^{(0.66)} \mathrm{Aa}$ & $7.53^{(1.07)} \mathrm{Aa}$ \\
\hline \multirow[t]{2}{*}{$260^{\circ} \mathrm{C}$} & $9.03^{(0.27)} \mathrm{Aa}$ & $10.05^{(0.55)} \mathrm{Bb}$ \\
\hline & \multicolumn{2}{|c|}{ TS24h (\%) } \\
\hline $200{ }^{\circ} \mathrm{C}$ & $16.82^{(1.23)} \mathrm{Aa}$ & $18.79^{(1.63)} \mathrm{Ab}$ \\
\hline $260^{\circ} \mathrm{C}$ & $16.68^{(0.34)} \mathrm{Aa}$ & $17.82^{(0.84)} \mathrm{Aa}$ \\
\hline
\end{tabular}

Means followed by the same uppercase letter, per column, or lower case, per line, do not differ by Scott-Knott test $(\mathrm{p}>0.05)$. The standard deviation is indicated in parentheses.

Particleboards produced with the Populus wood and heat-treated with a temperature of $190^{\circ} \mathrm{C}$ in times of 5,10 , 15,20 and $25 \mathrm{~min}$, and at $220^{\circ} \mathrm{C}$ for 5 and 10 min showed reductions between $14.9 \%$ and $25.0 \%$ for the TS24h property (Xiangquan et al., 1997). Panels produced with sugarcane bagasse and heat-treated at $260^{\circ} \mathrm{C}$ for $12 \mathrm{~min}$ had reductions for TS2h and TS24h of $26.6 \%$ and $47.0 \%$, respectively (Carvalho et al., 2015).

The samples without heat treatment and treated at 200 and $260^{\circ} \mathrm{C}$ did not meet the requirements of the EN 312 standard (ECS, 2003) and NBR14810 (ABNT, 2018) which establishes maximum value for TS24h of $14 \%$ for MDP of general use under moist conditions. However, all treatments met the NBR14810 (ABNT, 2018) standard for non-structural use in dry conditions, which determines the TS24h value of $22 \%$.

\subsection{Mechanical properties}

Table 5 shows the values of MOE, MOR and IB obtained for samples with and without heat treatment. The values of MOE differed statistically being between $19.77 \%$ and $27.24 \%$ lower than control treatment. All values of MOR of the heat-treated samples differed statistically from the control, reducing from $26.69 \%$ to $54.11 \%$, depending of the time and temperature used. The reduced density of heat-treated samples (Table 2), due to the release of pressing pressures, affected negatively the mechanical properties, since there is a positive linear relationship between the density of the material and its mechanical behavior (Maloney, 1993; Iwakiri et al., 2008; Ayrilmis et al., 2009).

The IB values of heat-treated samples differed statistically from the control, showing a reduction between $19.15 \%$ and $72.34 \%$ according to the increase of time and temperature (Table 5). The reduction of the internal bonding property using the heat treatment is related to the adhesive present in the panel that is also volatilized at the temperatures used in this work (Kaboorani \& Riedl, 2011; Stefanowski et al., 2016). According to Oliveira et al. (2017), the thermal degradation of the urea-formaldehyde adhesive starts at a temperature of $220^{\circ} \mathrm{C}$, with peak near $250^{\circ} \mathrm{C}$, factor that directly affects the mechanical properties of the panels.

Table 5. Effect of heat treatment on MOE, MOR and IB of MDP.

\begin{tabular}{cccc}
\multirow{2}{*}{ Treatments } & MOE & MOR & IB \\
\cline { 2 - 4 } Control & $2336.47^{(50.78)}$ & $17.65^{(1.08)}$ & $0.47^{(0.06)}$ \\
\hline $200^{\circ} \mathrm{C} / 5 \mathrm{~min}$ & $1874.44^{(108.87) *}$ & $12.94^{(0.42) *}$ & $0.37^{(0.03) *}$ \\
$200^{\circ} \mathrm{C} / 10 \mathrm{~min}$ & $1883.71^{(118.10) *}$ & $12.74^{(0.52) *}$ & $0.38^{(0.02) *}$ \\
$260^{\circ} \mathrm{C} / 5 \mathrm{~min}$ & $1758.20^{(126.78) *}$ & $9.60^{(1.12) *}$ & $0.38^{(0.05) *}$ \\
$260^{\circ} \mathrm{C} / 10 \mathrm{~min}$ & $1700.12^{(138.63) *}$ & $8.10^{(0.75) *}$ & $0.13^{(0.01) *}$
\end{tabular}

${ }^{*}$ Differences, at column, between treatments and the control by the Dunnett test $(\alpha=0.05)$.

There were interactions between the two temperatures (200 and $260^{\circ} \mathrm{C}$ ) and the two times ( 5 and $10 \mathrm{~min}$ ) used in the heat treatment in relation to MOE, MOR and IB (Table 6). The heat treatment time in association with the temperature of $200^{\circ} \mathrm{C} \mathrm{did}$ not have effect for any of the evaluated mechanical properties. However, the values of MOR and IB properties reduced with the increase of the heat treatment time in the $260^{\circ} \mathrm{C}$ temperature. 
Table 6. Interactions between temperature and heat treatment time on the MOE, MOR and IB of MDP.

\begin{tabular}{|c|c|c|}
\hline \multirow{2}{*}{ Temperature/Time } & \multicolumn{2}{|c|}{ MOE (MPa) } \\
\hline & $5 \mathrm{~min}$ & $10 \mathrm{~min}$ \\
\hline $200{ }^{\circ} \mathrm{C}$ & $1874.44^{(108.34)} \mathrm{Aa}$ & $1883.71^{(122.24)} \mathrm{Aa}$ \\
\hline \multirow{2}{*}{$260^{\circ} \mathrm{C}$} & $1758.19^{(101.63)} \mathrm{Aa}$ & $1700.12^{(143.05)} \mathrm{Ba}$ \\
\hline & \multicolumn{2}{|c|}{ MOR $(\mathrm{MPa})$} \\
\hline $200^{\circ} \mathrm{C}$ & $12.94^{(0.55)} \mathrm{Aa}$ & $12.74^{(0.59)} \mathrm{Aa}$ \\
\hline \multirow[t]{2}{*}{$260^{\circ} \mathrm{C}$} & $9.59^{(0.97)} \mathrm{Ba}$ & $8.10^{(0.66)} \mathrm{Bb}$ \\
\hline & \multicolumn{2}{|c|}{ IB $(\mathrm{MPa})$} \\
\hline $200{ }^{\circ} \mathrm{C}$ & $0.37^{(0.03)} \mathrm{Aa}$ & $0.38^{(0.03)} \mathrm{Aa}$ \\
\hline $260^{\circ} \mathrm{C}$ & $0.38^{(0.04)} \mathrm{Aa}$ & $0.13^{(0.01)} \mathrm{Bb}$ \\
\hline
\end{tabular}

Means followed by the same uppercase letter, per column, or lower case, per line, do not differ by Scott-Knott test $(\mathrm{p}>0.05)$. The standard deviation is indicated in parentheses.

Changing from $200{ }^{\circ} \mathrm{C}$ to $260{ }^{\circ} \mathrm{C}$ temperature with 10 minutes of heat treatment duration had significant effect on all properties (MOE, MOR and IB). There was significant effect for the MOR property at the time of $5 \mathrm{~min}$ too. In both cases, the heat-treated panels at $260^{\circ} \mathrm{C}$ obtained the lowest average values. The decrease in mechanical properties is associated with loss of panel mass caused by heating during heat treatment, as well as by the release of pressing stresses that promote the increase of empty spaces, acting as stress concentrators and decrease of panels density (Ayrilmis et al., 2009; Mendes et al., 2013a; Surdi et al., 2018).

Only heat-treated samples at a temperature of $260^{\circ} \mathrm{C}$ for $10 \mathrm{~min}$ did not meet the established minimum value by EN312 standard (ECS, 2003) of $0.30 \mathrm{MPa}$ and by NBR14810 (ABNT, 2018) of 0,35 MPa for the internal bonding. The samples without heat treatment and treated at $200{ }^{\circ} \mathrm{C}$ in both times meet the requirements of the EN 312 (ECS, 2003) and NBR14810 (ABNT, 2018) which establishes minimum value for MOR of $11 \mathrm{MPa}$ for MDP of internal use in dry conditions. For the MOE, only the samples without heat treatment (control) had a mean value higher than the minimum established value of $1950 \mathrm{MPa}$ (ECS, 2003; ABNT, 2018) for use in moist conditions. However, all treatments met the NBR14810 (ABNT, 2018) and EN 312 (ECS, 2003) for non-structural use in dry conditions, which determines $1600 \mathrm{MPa}$ for MOE.

\section{CONCLUSIONS}

The heat treatment at temperature of $200^{\circ} \mathrm{C}$ for 5 minutes was the most suitable for eucalyptus MDP, because the properties of TS2h and TS24h were improved and mechanical properties had smaller reductions.

For the dimensional stability of the samples, the temperature level had a greater influence in the first hours of immersion in water (TS2h), while for a longer period (TS24h) the heat treatment time was more effective. The temperature level influenced the mechanical properties more negatively than the heat treatment time.

Only the heat-treated samples at a temperature of $260^{\circ} \mathrm{C}$, in both treatment times, did not meet the requirements determined by the standards NBR14810 (ABNT, 2018) and EN 312 (ECS, 2003) for non-structural use in dry conditions.

\section{ACKNOWLEDGMENTS}

The authors would like to thank the "Fundação de Amparo à Pesquisa do Estado de Minas Gerais (FAPEMIG), Conselho Nacional de Desenvolvimento Científico e Tecnológico (CNPq) and Coordenação de Aperfeiçoamento de Pessoal de Nível Superior (CAPES)".

\section{SUBMISSION STATUS}

Received: 07 Oct. 2020

Accepted: 08 Jun. 2021

Associate editor: Geraldo Bortoletto Junior (i)

\section{CORRESPONDENCE TO}

Paula Gabriella Surdi

Universidade Federal de Viçosa, Viçosa, MG, Brasil.

e-mail: paulasurdi@gmail.com

\section{REFERENCES}

American Society for Testing and materials. ASTM D1037: Standard test methods for evaluating properties of wood-base fiber and particle panel materials. Philadelphia; 2012.

Associação Brasileira de Normas Técnicas. NBR 14810: Chapas de madeira aglomerada - requisitos. Rio de Janeiro; 2018.

Ayrilmis N, Laufenberg TL, Winandy JE. Dimensional stability and creep behavior of heat-treated exterior medium density fiberboard. European Journal of Wood and Wood Products 2009; 67: 287-295.

Ayrilmis N, Jarusombuti S, Fueangvivat V, Bauchongkol P. Effects of thermal treatment of rubberwood fibers on physical and mechanical properties of medium density fiberboard. Journal of Tropical Forest Science 2011; 23(1): 10-16.

Bekhta P. Effect of heat treatment on some physical and mechanical properties of birch plywood. European Journal of Wood and Wood Products 2020; 78: 683-691.

Borysiuk P, Jenczyk-Tolloczko I, Auriga R, Kordzikowski M. Sugar beet pulp as raw material for particleboard production. Industrial Crops and Products 2019; 141(1): 111829.

Carvalho AG, Mendes RF, Oliveira SL, Mendes LM. Effect of Postproduction Heat Treatment on Particleboard from Sugarcane Bagasse. Materials Research 2015; 18(1): 78-84.

Cavdar AD, Mengeloglu F, Karakus K, Tomak ED. Effect of Chemical Modification with Maleic, Propionic, and Succinic Anhydrides on Some Properties of Wood Flour Filled HDPE Composites. BioResources 2014; 9(4): 6490-6503. 
Del Menezzi CHS, Ribeiro RB, Sterndat GH, Teixeira DE, Okino EYA. Effect of thermal post-treatment on some surface related properties of oriented strandboards. Drvna Industrija 2008; 59(2): 61-67.

Del Menezzi CHS, Tomaselli I, Okino EYA, Teixeira DE, Santana MAE. Thermal modification of consolidated oriented strand boards: effects on dimensional stability, mechanical properties, chemical composition and surface color. European Journal of Wood and Wood Products 2009; 67(4): 383-396.

Deutsches Institut Für Normung. DIN 52362: Testing of wood chipboards, bending test, determination of bending strength. Germany; 1982.

European Committee for Standardization. EN 312: Particleboard: specifications. Bruxelas; 2003.

Figueroa MJM, Moraes PD. Comportamento da madeira a temperaturas elevadas. Ambiente Construído 2009; 9(4): 157-174.

Food and Agriculture Organization - FAO. FAOSTAT: Forestry production and trade (2020). Available from: http://www.fao.org/ faostat/en/\#data/FO

Hill C, Altgen M, Rautkari L. Thermal modification of wood-a review: chemical changes and hygroscopicity. Journal of Materials Science 2021; https://doi.org/10.1007/s10853-020-05722-z.

Indústria Brasileira de Árvores - IBÁ. Relatório 2019: ano base 2018. 80p. Brasília: 2019.

Iwakiri S, Stinghen ABM, Silveira EL, Zamarian EHC, Prata JG, Bronoski M. Influência da massa específica sobre as propriedades mecânicas de painéis aglomerados. Floresta 2008; 38(3): 487-493.

Kaboorani A, Riedl B. Improving performance of polyvinyl acetate (PVA) as a binder for wood by combination with melamine based adhesives. International Journal of Adhesion and Adhesives 2011; 31: 605-611.

Kocaefe D, Poncsak S, Tang J, Bouazara M. Effect of heat treatment on the mechanical properties of North American jack pine: thermogravimetric study. Journal of Materials Science 2010; 45: 681-687.

Lee SH, Lum WC, Zaidon A, Maminski M. Microstructural, mechanical and physical properties of post heat-treated melaminefortified urea formaldehyde-bonded particleboard. European Journal of Wood and Wood Products 2015; 73: 607-616.

Lee SH, Ashaari Z, Lum WC, Ang AF, Halip JA, Halis R. Chemical, physico-mechanical properties and biological durability of rubberwood particleboards after post heat-treatment in palm oil. Holzforschung 2017; 72 (2): 159-167.

Lunguleasa A, Ayrilmis N, Spirchez C, Özdemir F. Investigation of the effects of heat treatment applied to beech plywood. Drvna Industrija 2018; 69(4): 349-355.

Majka J, Czajkowski Ł, Olek W. Effects of cyclic changes in relative humidity on the sorption hysteresis of thermally modified spruce wood. BioResources 2016; 11: 5265-6275.

Maloney TM. Modern particleboard and dry-process fiberboard manufacturing. San Francisco: M. Freeman; 1993.

Melo RR, Muhl M, Stangerlin DM, Alfenas RF, Rodolfo Junior F. (2018). Properties of particleboards submitted to heat treatments. Ciência Florestal 2018; 28(2), 776-783.

Mendes RF, Bortoletto Júnior G, Almeida NF, Surdi PG, Barbeiro IN. Effect of thermal treatment on properties of OSB panels. Wood Science and Technology 2013a; 47:243-256.
Mendes RF, Bortoletto Júnior G, Almeida NF, Surdi PG, Barbeiro IN. Effects of thermal pre-treatment and variables of production on properties of OSB panels of Pinus taeda. Maderas: Ciencia y tecnologia 2013b; 15(2): 141-152.

Mendes, RF, Baleeiro, NS, Mendes, LM, Scatolino, MV, Oliveira, SL, Protásio, TP. Particleboard Panels Produced with Different Radial Positions of Pinus oocarpa Wood. Floresta e Ambiente 2018; 25(1): e00114514.

Narciso CRP, Reis, AHS, Mendes, JF, Nogueira ND, Mendes RF. Potential for the Use of Coconut Husk in the Production of Medium Density Particleboard. Waste and Biomass Valorization 2020; https://doi.org/10.1007/s12649-020-01099-X.

Nuopponen M, Vuorinen T, Jämsä S, Viitaniemi P. The effects of a heat treatment on the behavior of extractives in softwood studied by FTIR spectroscopic methods. Wood Science and Technology 2003; 37: 109-115.

Okino EYA, Teixeira DE, Del Menezzi CHS. Post-thermal treatment of oriented strandboard (OSB) made from Cypress (Cupressus glauca Lam.). Maderas: Ciencia y Tecnologia 2007; 9(3): 199-210.

Oliveira SL, Freire TP, Mendes LM, Mendes, RF. The Effect of Post-Heat Treatment in MDF Panels. Materials Research 2017; 20(1): 183-190.

Özgenç Ö, Durmaz S, Boyaci IH, Eksi-Kocak H. Determination of chemical changes in heat-treated wood using ATR-FTIR and FT Raman spectrometry. Spectrochimica Acta Part A: Molecular and Biomolecular Spectroscopy 2017; 171: 395-400.

Poncsák S, Shi SQ, Kocaefe D, Miller G. Effect of thermal treatment of wood lumbers on their adhesive bond strength and durability, J. Adhes. Sci. Technol 2007; 21(8): 745-754.

Ribeiro DP, Vilela AP, Silva DW, Napoli A, Mendes RF. Effect of Heat Treatment on the Properties of Sugarcane Bagasse Medium Density Particleboard (MDP) Panels. Waste and Biomass Valorization 2020; 11: 6429-6441.

Salca EA, Hiziroglu S. Evaluation of hardness and surface quality of different wood species as function of heat treatment. Materials and Design 2014; 62: 416-423.

Sivonen H, Maunu SL, Sundholm F, Jämsä S, Viitaniemi P. Magnetic Resonance Studies of Thermally Modified Wood. Holzforschung 2002; 56(6): 648-654.

Silva CMS, Vital BR, Carneiro ACO, Oliveira AC, Araújo SO, Magalhães MA. Energy properties of wood particles torrefied at different temperatures. Revista Árvore 2017; 41(4): e410404.

Silva CMS, Carneiro ACO, Vital BR, Figueiró CG, Fialho LF, Magalhães MA et al. Biomass torrefaction for energy purposes Definitions and an overview of challenges and opportunities in Brazil. Renewable and Sustainable Energy Reviews 2018; 82: 2426-2432.

Soratto DN, Silva CM, Vital BR, Carneiro ACO, Bianche JJ, Boschetti WN et al. Effect of thermal treatment variables on the thermogravimetric properties of eucalypt wood. Maderas: Ciencia y tecnología 2020; 22(2): 241-250.

Stefanowski BK, Curling SF, Ormondroyd GA. Evaluating mould colonisation and growth on MDF panels modified to sequester volatile organic compounds. International Wood Products Journal 2016; 7: 188-194. 
Surdi PG, Bortoletto Junior G, Castro VR. Evaluating the Effects of Removing Fines from Particleboards Manufactured from Amazonian Wood Residue. Floresta e Ambiente 2018; 25(3): e20170490.

Tarmian A, Mastouri A. Changes in moisture exclusion efficiency and crystallinity of thermally modified wood with aging. iForest Biogeosciences and Forestry 2019; 12(1): 92-97.

Tjeerdsma BF, Militz H. Chemical changes in hydrothermal treated wood: FTIR analysis of combined hydrothermal and dry heat-treated wood. Holz Roh Werkst 2005; 63: 102-111.

Uimonen T, Hautamäki S, Altgen M, Kymäläinen M, Rautkari L. Dynamic vapour sorption protocols for the quantification of accessible hydroxyl groups in wood. Holzforschung 2020; 74(4): 412-419.

Van der Stelt MJC, Gerhauser H, Kiel JHA, Ptasinski KJ. Biomass upgrading by torrefaction for the production of biofuels: A review. Biomass \& Bioenergy 2011; 35: 3748-62.
Wang L, Barta-Rajnai E, Skreiberg Ø, Khalil R, Czégény Z, Jakab E et al. Effect of torrefaction on physiochemical characteristics and grindability of stem wood, stump and bark. Applied Energy 2018; 227: 137-148.

Wang N, Zhan H, Zhuang X, Xu B, Yin X, Wang X et al. Torrefaction of waste wood-based panels: More understanding from the combination of upgrading and denitrogenation properties. Fuel Processing Technology 2020; 206: 106462.

Winandy JE, Krzysik AM. Thermal degradation of wood fibers during hot-pressing of MDF composites: part I. relative effects and benefits of thermal exposure. Wood and Fiber Science 2007; 39(3): 450-461.

Xiangquan Z, Renshu L, Weihong W, Anbin P. Heat Post-Treatment to Reduce Thickness Swelling of Particleboard from Fast-Growing Poplars. Journal of Forest Research 1997; 8(3): 188-190.

Yildiz S, Gümüşkaya E. The effects of thermal modification on crystalline structure of cellulose in soft and hardwood. Building and Environment 2007; 42(1): 62-67. 